\title{
GFORSETI
}

Forseti. Revista de Derecho. Volumen 8, № 11, Lima, 2020, pp. 84 - 107

\section{La actividad de fiscalización en el TUO de la LPAG: Revisión del maro legal del OSITRAN}

\author{
Milagros Maraví Sumar*
}

Resumen. - Este artículo analiza la facultad de fiscalización (denominada legalmente supervisión) del OSITRAN, a la luz de las nuevas disposiciones del Texto Único Ordenado de la Ley 27444, Ley del Procedimiento Administrativo General, aprobado por Decreto Supremo Nº 004-2019-JUS que regulan la materia.

Abstract. - This article analyzes OSITRAN's supervisory authority (legally called supervision), in light of the new provisions of the Sole Ordered Text of Law 27444, Law of General Administrative Procedure, approved by Supreme Decree No. 004-2019-JUS regulating the matter.

Palabras claves. - Fiscalización - Supervisión - Inspección - OSITRAN.

Keywords. - Audit - Supervision - Inspection - OSITRAN. 



\section{La actividad de fiscalización}

La actividad de fiscalización es una potestad administrativa invasiva de la esfera de derechos de los ciudadanos pues, para comprobar y asegurar el cumplimiento del marco normativo las entidades despliegan un abanico de facultades que se inmiscuyen en las actividades de las personas naturales o jurídicas con notable presencia y a veces discutible legalidad.

Un texto reciente de Andrés Boix Palop 1 comenta la polémica pública causada el 2011 por la decisión del municipio de San Sebastián en España de instaurar un sistema de recogida selectiva de residuos sólidos, que, incluida la atribución de potestades de inspección respecto de la basura de cada vecino, según la cual, la autoridad municipal podía revisarla a fin de verificar el cumplimiento de las obligaciones en materia de separación de residuos. Además de discutir la conveniencia misma de esta política, se produjo un intenso debate respecto de si los alcances del derecho a la intimidad personal y familiar, protegido constitucionalmente impedía el ejercicio de esta actividad municipal de inspección, llegando inclusive a cuestionarse si por medio de esta actividad pudiera rastrearse la orientación ideológica de los vecinos y se concluía que "permitir que un ayuntamiento pudiera indagar en la basura de sus vecinos afectaba claramente los derechos fundamentales y no era una restricción proporcionada de los mismos que se pudiera amparar en la consecución de fines públicos (en este caso, la garantía del correcto funcionamiento del sistema de recogida selectiva de basuras de la suficiente relevancia" 2. Finalmente, el Tribunal Supremo resolvió que "esta potestad de inspección se ajustaba plenamente a la Constitución y no suponía una invasión ilegítima del espacio de privacidad que protege el artículo $18.1 \mathrm{CE}$, por entender que era un mecanismo proporcional y ajustado a la consecución de ciertas finalidades públicas de control" 3 .

Es muy probable que casi todas las actividades de fiscalización o inspección puedan generar discusiones semejantes, dado que esta potestad se ejerce unilateralmente por las entidades públicas y siempre implica una invasión de la actividad privada, sea de personas naturales o jurídicas. Deviene muy relevante tener una regulación adecuada de esta potestad.

En esa orientación es que la ley de procedimiento administrativo ha incluido al Título IV de Procedimientos Especiales, que originalmente desarrollaba el procedimiento trilateral y el sancionador, un capítulo referido a la Actividad Administrativa de Fiscalización.

BOIX PALOP, Andres. “Las potestades administrativas de inspección y su expansión al amparo de razones de seguridad frente a los derechos fundamentales “. En La Página Definitiva. 1 de setiembre de 2015. Disponible en: http://www.lapaginadefinitiva.com/aboix/?p=1214.

2 Ídem.

3 Ídem. 
Por supuesto que esta actividad, que es transversal a todo el Estado no es nueva, pero no ha tenido una regulación general que le otorgue predictibilidad tanto para las entidades como a los administrados. Cada entidad, con facultad de adoptar medidas para verificar el cumplimiento del marco normativo de su competencia o inclusive de contratos, ha tenido su regulación propia, como es el caso del OSITRAN, cuyo marco normativo analizaremos en este texto, a la luz de las nuevas disposiciones del Texto Único Ordenado de la Ley 27444, Ley del Procedimiento Administrativo General, aprobado por Decreto Supremo 004-2019-JUS (en adelante, TUO de la LPAG).

En el grupo de trabajo que se constituyó en el Ministerio de Justicia y Derechos Humanos para actualizar la LPAG mediante el Decreto Legislativo 12724, se avizoró una oportunidad para incluir un capítulo sobre la actividad de fiscalización cuya regulación originalmente no estaba en la LPAG, porque considerábamos que no era propia de los procedimientos administrativos.

A este respecto, es conveniente mencionar que la LPAG contiene desde su origen otros temas no propios de los procedimientos administrativos. Por ejemplo, varios de los subcapítulos del título II, capítulo II sobre las Autoridad Administrativa que regula la competencia de las entidades, la colaboración entre entidades y el funcionamiento de los organismos colegiados, etc. que alguna vez se ha considerado extraer de ella para llevarlo a un Código Administrativo.

La relevancia que ha adquirido esta actividad de fiscalización y los problemas de la disparidad del ejercicio de su aplicación, nos motivó a incluirla en la reciente revisión de la LPAG.

Esta es una preocupación que no es privativa del Perú, pues la actividad de fiscalización ha ido adquiriendo gran relevancia a nivel mundial. El Profesor Manuel Rebollo Puig5 reflexiona sobre las razones para que esto haya ocurrido y se trata, según él de que el Estado se ha replegado como gestor para tomar un papel de "ordenador y garante". Por otro lado, también se ha ido replegando en los controles previos para reemplazarlos por controles posteriores; esto tanto en la "permisología previa" como en la ejecución continuada de actividades. Sin duda, también crisis financieras mundiales, como problemas graves sanitarios o desastres causados por la indisciplina urbanística y otras desgracias que se achacan a la falta de controles públicos suficientes han potenciado el interés en la actividad de fiscalización. Presupuesto de lo anterior, destaca Boix Palop es una "cada vez mayor incidencia de la regulación administrativa de muchísimas parcelas de nuestras vidas y de nuestras actividades económicas (...)” A más regulación, más inspección.

Por Resolución Ministerial 307-2016-JUS.

5 REBOLLO PUIS, Manuel. “LA ACTIVIDAD INSPECTORA en FUNCIÓN INSPECTORA Actas del VIII Congreso de la Asociación Española de Profesores de Derecho Administrativo INAP". Madrid, 2013, p 57. 
Si bien al inicio de este texto he descrito un caso que genera polémica por los alcances de la inspección, también hay casos, por ejemplo, las tragedias de mesa redonda o la discoteca Utopía o más recientemente el incendio en el que murieron trabajadores encerrados en un conteiner en los que se reclama la necesidad de mayor inspección.

De hecho, ante normas que deben cumplirse, la actividad de fiscalización de la administración parece inherente a ella; sin embargo, no todas las entidades tienen competencia de fiscalización atribuida. Por ejemplo, tiene facultad de fiscalización en nuestro país, por ejemplo, SUNAT, OSITRAN, OSINERGMIN, INDECOPI u OEFA, los Gobiernos Regionales y Municipales. No tiene facultades fiscalizadoras algunas entidades como el Instituto de Investigaciones de la Amazonía Peruana (IIAP) o el Instituto Geofísico del Perú (IGP).

A falta de una regulación general, cada una de las entidades que tiene facultad de fiscalización ha desarrollado su propio ordenamiento jurídico para esta actividad; que, por lo demás, tiene nombres diferentes para lo mismo. La facultad de inspección es conocida también como fiscalización o supervisión. Sin embargo, también recibe nombres como vigilancia, inspección o control.

Por la diversidad de nomenclatura, el artículo 239.2 del nuevo TUO de al LPAG dispone que "Independientemente de su denominación, las normas especiales que regulan esta función se interpretan y aplican en el marco de las normas comunes del presente capítulo, aun cuando conforme al marco legal sean ejercidos por personas naturales o jurídicas privadas".

Esta disposición es coincidente con el artículo II del mismo TUO de la LPAG que establece lo siguiente:

“Artículo II.- Contenido

1. La presente Ley contiene normas comunes para las actuaciones de la función administrativa del Estado y, regula todos los procedimientos administrativos desarrollados en las entidades, incluyendo los procedimientos especiales.

2. Las leyes que crean y regulan los procedimientos especiales no podrán imponer condiciones menos favorables a los administrados que las previstas en la presente Ley.

3. Las autoridades administrativas, al reglamentar los procedimientos especiales, cumplirán con seguir los principios administrativos, así como los derechos y deberes de los sujetos del procedimiento, establecidos en la presente Ley". (Énfasis agregado)

Es decir que estas normas son aplicables no solo a procedimientos especiales, sino a toda actuación administrativa. Es una realidad que varias entidades han aprobado Decretos Legislativos para exceptuarse de diversos aspectos de esta ley, 
como es el caso, por ejemplo de la SUNAT6. Sin embargo, respecto de los procedimientos especiales y la actuación administrativa en general, hay que tener presente que, a nivel judicial, siempre será discutible lo actuado en contravención a las normas del TUO de la LPAG que son estándar mínimo.

\section{Definición de la actividad de fiscalización en el TUO de la LPAG}

El artículo 237.1 del TUO de la LPAG, define la actividad de fiscalización:

"La actividad de fiscalización constituye el conjunto de actos y diligencias de investigación, supervisión, control o inspección sobre el cumplimiento de las obligaciones, prohibiciones y otras limitaciones exigibles a los administrados, derivados de una norma legal o reglamentaria, contratos con el Estado u otra fuente jurídica, bajo un enfoque de cumplimiento normativo, de prevención del riesgo, de gestión del riesgo y tutela de los bienes jurídicos protegidos".

Una primera incógnita a este respecto es que dado que esta legislación es reciente, no existe uniformidad en la nomenclatura que las entidades utilizan para denominar esta actividad. Supervisión e inspección son sólo algunos de los términos.

Por ejemplo, en el OSITRAN la actividad de inspección se denomina supervisión7

6 El Decreto Legislativo 311, en su cuarta disposición complementaria final dispone lo siguiente: QUINTA.- Aplicación supletoria de la Ley 27444, Ley del Procedimiento Administrativo General modificada por el Decreto Legislativo $\mathrm{N}^{\mathrm{O}} 1272$.

Los procedimientos especiales seguidos ante la SUNAT, el Tribunal Fiscal y otras Administraciones Tributarias, se rigen supletoriamente por la Ley 27444, Ley de Procedimiento Administrativo General, modificada por el Decreto Legislativo 1272; no siéndoles aplicable lo previsto en los numerales 1 y 2 del artículo II del Título Preliminar de dicha Ley.

La SUNAT, el Tribunal Fiscal y otras Administraciones Tributarias se sujetarán a los principios de la potestad sancionadora previstos en los artículos 168 y 171 del Código Tributario, no siéndole de aplicación lo dispuesto en el artículo 230 de la Ley 27444, Ley de Procedimiento Administrativo General, según modificatoria por el Decreto Legislativo 1272.

7 Esto se verifica en el las siguientes normas:

- En el artículo 2, inciso c, del Reglamento General de Supervisión de OSITRAN, aprobado por Resolución de Consejo Directivo 024-2011-CD-OSITRAN.

"Artículo No 2.- Definiciones

Para efectos de este Reglamento, los términos que inicien con mayúscula tendrán el significado que les asigna el Reglamento General de OSITRAN, o las Definiciones contenidas en este artículo, según corresponda

(...)

c) Función Supervisora: Es la función que permite a OSITRAN verificar el cumplimiento de las obligaciones legales, contractuales, técnicas o administrativas, por parte de las Entidades Prestadoras, en los aspectos técnicos, operativos, comerciales y administrativos, en el ámbito de su competencia. (...)"

- $\quad$ En el artículo 3.1, inciso a, de la Ley 27332, Ley Marco de los Organismos Reguladores de la Inversión Privada en los Servicios Públicos.

"Artículo 3.- Funciones

3.1 Dentro de sus respectivos ámbitos de competencia, los Organismos Reguladores ejercen las siguientes funciones:

a) Función supervisora: comprende la facultad de verificar el cumplimiento de las obligaciones legales, contractuales o técnicas por parte de las entidades o actividades supervisadas, así como la facultad de verificar el cumplimiento de cualquier mandato o 
y el término fiscalización está vinculado exclusivamente a la identificación de la comisión de infracciones en el procedimiento sancionadors. Lo señalado anteriormente también es aplicable para el OEFA9. En el caso de la Ley Orgánica de Municipalidades, a dicha actividad se le ha denominado vigilancia o control de cumplimiento10. Por eso, como ya mencionamos, el TUO de la LPAG (artículo 237.2) refiere que todas las actividades de fiscalización o inspección, sin perjuicio de su denominación, se rigen por las normas de este capítulo.

Como señala la definición, la actividad de fiscalización se organiza atendiendo a tres finalidades:

- Asegurar el cumplimiento de las normas u obligaciones, para prevenir incumplimientos, bajo un enfoque de riesgo.

- Revertir el incumplimiento de las mismas.

- Cautelar bienes jurídicos y asegurar derechos de las personas.

En efecto, por la fiscalización se descubren hechos u omisiones antes no conocidos o se comprueban otros ya advertidos, para prevenir incumplimientos, corregir incumplimientos detectados y cautelar bienes jurídicos y asegurar derechos de las personas.

Un eficiente sistema de fiscalización i) abona a que los actores privados del sector se comporten de manera correcta porque saben que serán supervisados y,

resolución emitida por el Organismo Regulador o de cualquier otra obligación que se encuentre a cargo de la entidad o actividad supervisadas."

$(\ldots)$

8 En el artículo 3.1, inciso a, de la Ley 27332, Ley Marco de los Organismos Reguladores de la Inversión Privada en los Servicios Públicos.

"Artículo 3.- Funciones

3.1 Dentro de sus respectivos ámbitos de competencia, los Organismos Reguladores ejercen las siguientes funciones:

d) Función fiscalizadora y sancionadora: comprende la facultad de imponer sanciones dentro de su ámbito de competencia por el incumplimiento de obligaciones derivadas de normas legales o técnicas, así como las obligaciones contraídas por los concesionarios en los respectivos contratos de concesión.

(...)

9 Esto se verifica en los artículos 3 y 5 del Reglamento de Supervisión de OEFA, aprobado por Resolución de Consejo Directivo 006-2019-OEFA-CD:

"Artículo 3.- Finalidad

La función de supervisión tiene por finalidad verificar el cumplimiento de las obligaciones fiscalizables de los titulares de actividades cuya supervisión se encuentra a cargo del OEFA y las funciones de fiscalización ambiental a cargo de las EFA; así como, promover la subsanación voluntaria de los incumplimientos de dichas obligaciones.

Dicha finalidad se enmarca en un enfoque de cumplimiento normativo, de prevención y gestión del riesgo, para garantizar una adecuada protección ambiental".

"Artículo 5.- Definiciones

Para efectos del presente Reglamento, se aplican las siguientes definiciones:

Acción de supervisión: Todo acto del supervisor que, bajo cualquier modalidad, tenga por objeto verificar el cumplimiento de las obligaciones fiscalizables y funciones a cargo de las EFA.

$(\ldots)^{\prime \prime}$

10 Ver Ley 27972, Ley Orgánica de Municipalidades: 
eventualmente sancionados; y ii) con la información recopilada en estas actividades, se conllevaría a mejorar las políticas públicas.

No es el objetivo de la actividad de fiscalización, sancionar, sino la adecuación de la actuación de los administrados al ordenamiento jurídico (sea que se trate de una norma o contrato).

Tirado Barreda11 destaca muy acertadamente cuatro características fundamentales de la función de inspección o fiscalización:

Al tratarse de una potestad administrativa, se rige por el principio de legalidad, debe ser atribuida por ley o norma con tal rango expresamente y ceñirse a sus límites.

Asimismo, estamos ante una potestad que se ejerce unilateralmente, sin requerirse voluntad de terceros o de los mismos administrados que son objeto de la inspección. Aun cuando se trate de la potestad de fiscalización de obligaciones contractuales, la potestad de fiscalización no emana del contrato sino de la Ley.

Por otro lado, Tirado Barreda indica que esta potestad es siempre restrictiva o limitativa de derechos, lo que es de fácil comprobación pues siempre implica el ejercicio de facultades tales como ingreso a locales, verificar documentación, efectuar pruebas diversas, interrogar, etc.

Finalmente, precisa que el ejercicio de la potestad de fiscalización es discrecional en el momento en que se decide su iniciación o aplicación y reglada en el momento de su ejecución. En efecto, la entidad sólo tendrá las facultades para fiscalizar expresamente previstas en el marco legal aplicable y no otras. En el TUO de la LPAG se ha previsto un artículo específico con tales facultades, el $240^{\circ}$. En este punto, hay que tener presente, que si bien la decisión de fiscalizar es discrecional, siempre está sujeta a los principios del TUO de la LPAG. De hecho, muchas entidades, como es el caso del OSITRAN, aprueban planes de supervisión anuales, los cuales dan cierta predictibilidad y reduce el espacio de la discrecionalidad, aunque eso no cambia el carácter discrecional de la decisión de inspeccionar.

La actividad de fiscalización se rige por los principios del TUO de la LPAG, principalmente el de Proporcionalidad (llamado de Razonabilidad), según el cual esta facultad sólo debe orientarse a los hechos materia de indagación y mediante la potestad menos restrictiva para el administrado, que sea requerida para asegurar la tutela del interés protegido. Una actuación desproporcionada, deviene en ilícita, aunque se cuente con facultades de fiscalización. A este respecto, señala Rebollo Puig12 que:

11 TIRADO BARREDA, José Antonio. "Reflexiones en torno a la potestad de inspección o fiscalización de la administración pública". En Revista Derecho \& Sociedad N³7, Lima, 2011, p. 253.

12 REBOLLO PUIS, Manuel. “La actividad inspectora en función inspectora Actas del VIII Congreso de la Asociación Española de Profesores de Derecho Administrativo INAP”, Madrid, 2013, p. 70. 
"Conforme a este principio, hay que entender que las leyes, aunque hayan investido a la Administración de las más amplias y severas potestades de inspección, solo las ha conferido para su ejercicio en cada caso en la medida imprescindible. Así, sólo se deben buscar los hechos que puedan tener relevancia para la investigación y hacerlo mediante la potestad menos restrictiva para el administrado, ejerciéndola a su vez en la forma y medida menos lesiva y, aun dentro de ello, solo si supone un sacrificio justificado por la eventual lesión de los intereses públicos que trata de conocerse y combatirse $(\ldots)^{\prime \prime}$.

\section{Actividad de fiscalización o procedimiento administrativo}

Otro tema que se debate es si la actividad de inspección es un procedimiento administrativo.

La definición del artículo $237^{\circ}$ alude a un conjunto de "actos y diligencias" de investigación, supervisión, control o inspección. Sin embargo, la Actividad de Fiscalización, está en el Título IV de procedimientos especiales, conjuntamente con el trilateral y el sancionador.

Por otro lado, en el Grupo de Trabajo, no le hemos llamado "procedimiento" sino "actividad" y no tengo recuerdo que se quisiera regular como tal. Asimismo, es claro que la actividad de fiscalización no está dirigida a la emisión de un acto administrativo, lo que es característico de la definición del procedimiento administrativo13.

A este respecto, el MINJUS ha opinado en la Consulta Jurídica 005-2017JUS/DGDOJ «23.2.17» sobre la naturaleza de la Actividad Administrativa de Fiscalización, concluyendo en que no estamos ante un procedimiento administrativo.

En efecto, el MINJUS ha precisado lo siguiente:

“21 Sobre el particular, el artículo 228-A la norma citada supra se encarga de desarrollar la definición de la actividad administrativa de fiscalización según la cual dicha actividad "constituye el conjunto de actos y diligencias de investigación, supervisión, control o inspección sobre el cumplimiento de las obligaciones, prohibiciones y otras limitaciones exigibles a los administrados, derivados de una norma legal o reglamentaria, contratos con el Estado u otra fuente jurídica, bajo un enfoque de cumplimiento normativo, de prevención del riesgo, de gestión del riesgo y tutela de los bienes jurídicos protegidos.

22. En la Exposición de Motivos del Decreto Legislativo 1272 se establece que, 'respecto de la fiscalización [se instaura] la finalidad, el objeto, el

13 Artículo 29.- Definición de procedimiento administrativo

Se entiende por procedimiento administrativo al conjunto de actos y diligencias tramitados en las entidades, conducentes a la emisión de un acto administrativo que produzca efectos jurídicos individuales o individualizables sobre intereses, obligaciones o derechos de los administrados. (Enfasis agregado). 
enfoque, los alcances, los límites, los derechos, deberes, las reglas básicas aplicables a las medidas correctivas y cautelares, así como garantías tanto para el fiscalizado como para el fiscalizador'.

23. A juzgar por los argumentos antes expuestos, esta Dirección General considera que la actividad administrativa de fiscalización, no constituye un procedimiento administrativo, pues su enfoque está dirigido a la realización de actividades destinadas a advertir el cumplimiento o no de la norma imperativa atribuible al administrado, sumado a ello, su fin no está encaminado a la emisión de un pronunciamiento o acto administrativo. (Enfasis agregado)

24. En efecto, de acuerdo a lo establecido en el vigente artículo 228-A de la Ley 27444, incorporado por el artículo 5 del Decreto Legislativo 1272, y justificado por su Exposición de Motivos, a través de la actividad administrativa de fiscalización se busca, de manera preventiva, verificar el cabal cumplimiento de las obligaciones o prohibiciones exigidas al administrado a partir de una norma o contrato. El recientemente incorporado capítulo instaura dispositivos legales que permiten el desarrollo de dicha actividad cuyo ejercicio es de manera preventiva y potestativa para la administración.

25. Afirmar la naturaleza procedimental de la actividad administrativa de fiscalización constituye un error de interpretación de la norma, más aún si se tiene en consideración lo prescrito en el artículo 228-G [de la Ley 27444, modificada por el Decreto Legislativo 1272] el cual regula las formas de conclusión de dicha función, no constituyendo ninguna de ellas un acto administrativo, tales como la certificación de conformidad, la recomendación de mejoras o correcciones, la advertencia de incumplimientos, y más claramente, la recomendación para el inicio de un procedimiento sancionador. (Enfasis agregado).

26. No obstante, podría existir un error de percepción respecto de la forma de conclusión de la actividad de fiscalización consistente en disponer la 'adopción de una medida correctiva' confundiéndola con un acto administrativo. Lo cierto es que, en un procedimiento administrativo sancionador, la adopción de tal medida va aparejada a la determinación de la responsabilidad del administrado y a la imposición de una sanción, contenida en un acto administrativo que pone fin a dicho procedimiento. Sin embargo, dado que en las actuaciones administrativas de fiscalización no existe la determinación de responsabilidad ni sanción, la disposición de la autoridad fiscalizadora para que el fiscalizado 'adopte una medida correctiva' solo constituye una medida de naturaleza precautoria o preventiva acorde con la naturaleza de dicha función fiscalizadora, cuya inobservancia recién acarrearía la apertura de un procedimiento sancionador, no por la omisión en sí misma, sino por la conducta infractora que originó que se disponga la adopción de dicha medida correctiva" 14 .

14 Ministerio de Justicia. "Guía de opiniones jurídicas emitidas por la Dirección General de Desarrollo y Ordenamiento Jurídico". En https://www.minjus.gob.pe/wpcontent/ uploads/2017/04/MINJUS-DGDOJ-GUIA-DE-OPINIONES-DEL-TUO-DE-LA27444.pdf. pg. 149-150. 
En ese sentido, el MINJUS entiende que la fiscalización tiene fundamentalmente carácter preventivo para verificar el cabal cumplimiento de las obligaciones o prohibiciones exigidas al administrado a partir de una norma o contrato. Asimismo que su objetivo es diferente al de un procedimiento administrativo, consistiendo en advertir el cumplimiento o no de una obligación atribuible al administrado por norma o contrato.

Sin embargo, autores como Juan Carlos Morón15 le reconocen el carácter de procedimiento administrativo por haberse ubicado su tratamiento en este capítulo de "procedimientos especiales". Este mismo autor advierte que, en la medida en que la actividad de fiscalización no tiene como objetivo el que se dicte un acto administrativo que tenga efectos sobre los administrados, sino que es uno especial que no genera efectos jurídicos en la esfera del administrado, no se aplican las garantías del procedimiento administrativo o del sancionador en particular.

Según su parecer, la constancia de conformidad, recomendación de mejoras, advertencia de existencia de incumplimientos, recomendación de inicio de PAS, serían actos de trámite o de gravamen y, por lo tanto, no serían impugnables.

Rebollo Puig indica en cambio que16:

“(...) hay que concluir que no estamos ante un verdadero y propio procedimiento administrativo sino que ni siquiera rigen los requisitos de la práctica de la prueba en el procedimiento que imponen a la Administración comunicarla a los interesados "con antelación suficiente", indicando lugar, fecha y hora, así como la advertencia de que "pueden nombrar técnicos para que le asistan" (art 81 LRJAP). Aquí no hay nada de eso." El mismo autor, en seguida, indica que el legislador puede procedimentalizar ciertas ramas de la inspección cuando y en la medida que lo considere oportuno. Y, en efecto, lo ha hecho en algunos sectores. Con todo, en la mayoría de los casos se trata de una procedimentalización parcial (...) pero, "se trata de excepciones legales que no niegan que con carácter general, la inspección no tienen por qué estar ni está sometida a los principios y reglas de un procedimiento administrativo en sentido estricto" 17.

A nuestro entender, la Actividad de Fiscalización no es un procedimiento administrativo especial o así lo hubiéramos denominado y, principalmente porque sólo está dirigido a la verificación de hechos de cumplimiento o incumplimiento, no a modificar la situación jurídica concreta de los administrados o siquiera a declararla.

Si la entidad, dicta medidas provisionales o inclusive medidas correctivas en el

15 MORÓN URBINA, Juan Carlos. “Comentarios a la ley del Procedimiento Administrativo General". En Gaceta Jurídica, Lima 2017, Tomo II, p. 311.

16 REBOLLO PUIS, Manuel. "La actividad inspectora en función inspectora Actas del VIII Congreso de la Asociación Española de Profesores de Derecho Administrativo INAP”, Madrid 2013, p. 75.

17 REBOLLO PUIS, Manuel. “La actividad inspectora en función inspectora Actas del VIII Congreso de la Asociación Española de Profesores de Derecho Administrativo INAP", Madrid 2013, p. 76. 
marco de una actividad de fiscalización porque tienen dichas facultades, esos actos seguirán el tratamiento que la ley le da a tales, pero no es el objetivo de una Actividad de Fiscalización dictar este tipo de actos. Tampoco rigen las reglas de prueba o notificación anticipada para que se cuente con asistencia legal o técnica. Si es bueno precisar, que si bien no está sujeto a las reglas de procedimiento administrativo, si está sujeta, como toda actividad administrativa, a los principios del Título preliminar del TUO de la LPAG y, asimismo, al capítulo mismo de Actividad de Fiscalización.

En el caso del OSITRAN, si bien el Reglamento General de Supervisión se refiere en su título III al "Procedimiento de supervisión", en el Capítulo $\mathrm{N}^{0} 1$ a las "Normas Generales del Procedimiento" y en cada modalidad de supervisión, alude a que regula el procedimiento, la referida norma, no le da a los mismos el tratamiento de un procedimiento administrativo.

\section{Actividad de fiscalización y otras fiscalizaciones}

Es conveniente diferenciar la actividad de fiscalización de la LPAG de otras fiscalizaciones; así, no rigen las normas de la LPAG para el Control gubernamental intra administrativo; tampoco para la fiscalización posterior documental en procedimientos administrativos, regulada por el artículo 34 del TUO de la LPAG y por lineamientos aprobado por la PCM y reglamentos de fiscalización posterior aleatoria aprobados por cada entidad y que se limita a verificación de la veracidad de documentación. Asimismo, no se aplica al procedimiento administrativo sancionador que tiene su propia regulación y que no siempre se inicia por fiscalización previa ya que puede iniciarse también por una denuncia.

\section{Inicio de oficio}

Como ya hemos señalado, La actividad de fiscalización se inicia siempre de oficio. Conforme al artículo 240. 1; Los actos y diligencias de fiscalización se inician siempre de oficio, bien por propia iniciativa o como consecuencia de orden superior, petición motivada o por denuncia. Así también lo reconoce el Reglamento general de Supervisión del OSITRAN en su artículo 17.

Es preciso tener presente que, si la fiscalización de inicia por denuncia de terceros, debería ser tramitada conforme al artículo $114.3^{\circ}$ del TUO de la LPAG que dispone que "su presentación obliga a practicar las diligencias preliminares necesarias y, una vez comprobada su verosimilitud, a iniciar de oficio la respectiva fiscalización. El rechazo de una denuncia debe ser motivado y comunicado al denunciante, si estuviese individualizado". (Énfasis agregado).

\section{Competencia para la actividad de fiscalización}

El artículo 239.1 del TUO de la LPAG indica que "Solamente por Ley o Decreto Legislativo puede atribuirse la facultad de fiscalización a las entidades". Si bien la facultad de fiscalización parece inherente a las entidades públicas a cargo de 
asegurar el cumplimiento de un marco normativo, eso no implica que no deba ser expresamente atribuida con una norma con rango de ley como cualquier otra competencia; máxime que al ser una actividad restrictiva de derechos fundamentales, debe ser realizada con reglas preestablecidas, con mínima discrecionalidad y con alta predictibilidad en los tres niveles de gobierno.

En el caso de OSITRAN, por ejemplo, este requisito se cumple a cabalidad, ya que la Ley de creación del OSITRAN N 26917, le atribuye la competencia de fiscalización con el nombre de supervisión, como veremos a continuación:

"Artículo 7.- Funciones

7.1. Las principales funciones de OSITRAN son las siguientes:

a) Administrar, fiscalizar y supervisar los contratos de concesión con criterios técnicos desarrollando todas las actividades relacionadas al control posterior de los contratos bajo su ámbito".

Asimismo, la Ley 27332 - Ley Marco de los organismos reguladores prevé dentro de sus funciones, de manera más precisa en su artículo 3.1 a) la función supervisora, conforme a la siguiente descripción:

“a) Función supervisora: comprende la facultad de verificar el cumplimiento de las obligaciones legales, contractuales o técnicas por parte de las entidades o actividades supervisadas, así como la facultad de verificar el cumplimiento de cualquier mandato o resolución emitida por el Organismo Regulador o de cualquier otra obligación que se encuentre a cargo de la entidad o actividad supervisadas".

Asimismo, el Reglamento General del OSITRAN, norma reglamentaria de las leyes 26917, 27332 y 28337 aprobado por el DS 044-2006-PCM dispone en su artículo $1^{\circ}$ entre las definiciones la siguiente:

“b) Actividades de supervisión: Actos del personal de OSITRAN o autorizado por éste que, bajo cualquier modalidad, tengan por objeto obtener información y/o verificar el cumplimiento de obligaciones legales, contractuales, técnicas, administrativas, o aquellas contraídas directamente ante OSITRAN por parte de las Entidades Prestadoras, sobre aspectos técnicos, operativos, comerciales y administrativos, en el ámbito de su competencia".

Finalmente, el Reglamento General de Supervisión de OSITRAN, aprobado por Resolución de Consejo Directivo No 024-2011-CD-OSITRAN, también contiene entre sus definiciones esta misma en su artículo $\mathrm{N}^{\circ} 2$, inciso c):

“c) Función Supervisora: Es la función que permite a OSITRAN verificar el cumplimiento de las obligaciones legales, contractuales, técnicas o administrativas, por parte de las Entidades Prestadoras, en los aspectos técnicos, operativos, comerciales y administrativos, en el ámbito de su competencia".

Esta competencia atribuida legalmente a OSITRAN es asignada a los órganos correspondientes a través de su ROF. Así, en el caso del OSITRAN, de acuerdo a 
los artículos $52^{\circ}$ y $54^{\circ}$ del ROF de OSITRAN, aprobado por D.S. 012-2015-PCM, el órgano de línea competente para efectuar las actividades de supervisión y fiscalización es la Gerencia de Supervisión y Fiscalización, la cual se divide en Jefaturas según el tipo de actividad a fiscalizar (aeropuertos, puertos, trenes y metro y la red vial nacional).

\section{Facultades de las Entidades que cuentan con competencia para la actividad de fiscalización}

El artículo 240 del TUO de la LPAG prevé las facultades de las entidades que realizan actividad de fiscalización.

Esto es muy relevante tenerlo presente porque si una entidad tiene facultad de fiscalización por Ley o Decreto Legislativo, en función del TUO de la LPAG, adquiere estas facultades, sin perjuicio de las que tenga por "leyes especiales" (ver inciso 8 de este artículo).

\section{¿Cuáles son esas facultades?}

Conforme al artículo 240.2, La Administración Pública en el ejercicio de la actividad de fiscalización está facultada para realizar lo siguiente:

1. Requerir al administrado objeto de la fiscalización, la exhibición o presentación de todo tipo de documentación, expedientes, archivos u otra información necesaria, respetando el principio de legalidad.

El acceso a la información que pueda afectar la intimidad personal o familiar, así como las materias protegidas por el secreto bancario, tributario, comercial e industrial y la protección de datos personales, se rige por lo dispuesto en la Constitución Política del Perú y las leyes especiales.

2. Interrogar a las personas materia de fiscalización o a sus representantes, empleados, funcionarios, asesores y a terceros, utilizando los medios técnicos que considere necesarios para generar un registro completo y fidedigno de sus declaraciones.

La citación o la comparecencia personal a la sede de las entidades administrativas se regulan por los artículos 67 y 68.18

18 En el nuevo TUO se trata de los artículos 69 y 70 sobre comparecencia personal Artículo 69.- Comparecencia personal

69.1 Las entidades pueden convocar la comparecencia personal a su sede de los administrados sólo cuando así le haya sido facultado expresamente por ley.

69.2 Los administrados pueden comparecer asistidos por asesores cuando sea necesario para la mejor exposición de la verdad de los hechos.

69.3 A solicitud verbal del administrado, la entidad entrega al final del acto, constancia de su comparecencia y copia del acta elaborada.

(Texto según el artículo 58 de la Ley No 27444)

Artículo 70.- Formalidades de la comparecencia

70.1 El citatorio se rige por el régimen común de la notificación, haciendo constar en ella lo siguiente: 
3. Realizar inspecciones, con o sin previa notificación, en los locales y/o bienes de las personas naturales o jurídicas objeto de las acciones de fiscalización, respetando el derecho fundamental a la inviolabilidad del domicilio cuando corresponda.

4. Tomar copia de los archivos físicos, ópticos, electrónicos u otros, así como tomar fotografías, realizar impresiones, grabaciones de audio o en video con conocimiento previo del administrado y, en general, utilizar los medios necesarios para generar un registro completo y fidedigno de su acción de fiscalización.

5. Realizar exámenes periciales sobre la documentación y otros aspectos técnicos relacionados con la fiscalización.

6. Utilizar en las acciones y diligencias de fiscalización equipos que consideren necesarios. Los administrados deben permitir el acceso de tales equipos, así como permitir el uso de sus propios equipos, cuando sea indispensable para la labor de fiscalización.

7. Ampliar o variar el objeto de la acción de fiscalización en caso que, como resultado de las acciones y diligencias realizadas, se detecten incumplimientos adicionales a los expresados inicialmente en el referido objeto.

8. Las demás que establezcan las leyes especiales.

De acuerdo a la doctrina, existen dos clases de facultades de fiscalización o potestades de inspección. Unas son ordenatorias y otras conformatorias19.

Las primeras imponen al administrado un deber de hacer (suministrar, documento, contestar preguntas, comparecer). Las segundas permiten a la administración pasar a la acción: acceso a locales y documentos y al administrado solo le corresponde "dejar hacer". Así, se considera ordenatoria por ejemplo, el

70.1.1 El nombre y la dirección del órgano que cita, con identificación de la autoridad requirente; 70.1.2 El objeto y asunto de la comparecencia;

70.1.3 Los nombres y apellidos del citado;

70.1.4 El día y hora en que debe comparecer el citado, que no puede ser antes del tercer día de recibida la citación, $y$, en caso de ser previsible, la duración máxima que demande su presencia. Convencionalmente puede fijarse el día y hora de comparecencia;

70.1.5 La disposición legal que faculta al órgano a realizar esta citación; y,

70.1.6 El apercibimiento, en caso de inasistencia al requerimiento.

70.2 La comparecencia debe ser realizada, en lo posible, de modo compatible con las obligaciones laborales o profesionales de los convocados.

70.3 El citatorio que infringe alguno de los requisitos indicados no surte efecto, ni obliga a su asistencia a los administrados.

(Texto según el artículo 59 de la Ley No 27444)

19 REBOLLO PUIS, Manuel. “LA ACTIVIDAD INSPECTORA en FUNCIÓN INSPECTORA Actas del VIII Congreso de la Asociación Española de Profesores de Derecho Administrativo INAP". Madrid, 2013, p 60. 
mandato de exhibición o entrega de documentos y conformatoria, por ejemplo, la realización de peritajes.

Respecto de las facultades hay algunos temas relevantes que analizaremos a continuación:

\section{i. La inviolabilidad de domicilio en personas jurídicas}

Para efectos de la supervisión cualquier entidad, entre ellas el OSITRAN puede acceder a locales abiertos al público o no. El artículo 240.2.3 permite oponer a las inspecciones el derecho a la inviolabilidad de domicilio.

El Tribunal Constitucional ha señalado, con carácter enunciativo (Sentencia del Tribunal Constitucional Exp. 04972-2006-PA/TC), que las personas jurídicas pueden ser titulares de derechos fundamentales como el secreto bancario y la reserva tributaria, la autodeterminación informativa, la inviolabilidad de domicilio, el secreto e inviolabilidad de las comunicaciones y documentos privados y a la nacionalidad. Además, ha reconocido que estas gozan de libertades como las de información y expresión, de creación intelectual, artística, técnica y científica, de residencia y de reunión, sólo se extiende a los espacios físicos que son indispensables para que puedan desarrollar su actividad sin intromisiones ajenas, por constituir el centro de dirección de la sociedad o de un establecimiento dependiente de la misma o servir a la custodia de los documentos u otros soportes de la vida diaria de la sociedad o de su establecimiento que quedan reservados al conocimiento de terceros.

En el caso de la normativa de OSITRAN, conforme al artículo 5 de la Ley Marco de los Organismos Reguladores de la Inversión Privada en los Servicios Públicos, LEY 27332 “los Organismos Reguladores gozarán de las facultades establecidas en el Título I del Decreto Legislativo 807".

Cabe precisar el artículo 5 se refiere a "facultades fiscalizadoras y sancionadoras específicas", pero entendemos que operan para ambas competencias.

Por otro lado, aunque el artículo 2 a) del Título I del Decreto Legislativo 807 indica que estas facultades no son taxativas, debe entenderse que no lo son, sólo si son atribuidas facultades por otras normas con rango de ley y no como habilitación genérica porque facultades como estás sólo pueden atribuirse expresamente por ley.

De la revisión de estas normas, podemos comprobar que el OSITRAN sí tiene atribuidas por su marco normativo la mayoría de cada una de las facultades previstas en el artículo 238.2 del TUO de la LPAG.

Sin embargo, la facultad de "ampliar o variar el objeto de la acción de fiscalización en caso que, como resultado de las acciones y diligencias realizadas, se detecten incumplimientos adicionales a los expresados inicialmente en el referido objeto", no está considerada expresamente en las normas del OSITRAN. 
En todo caso, desde la vigencia de este capítulo de Actividad de Fiscalización, OSITRAN cuenta con dicha facultad y debería considerarla incluida en su Reglamento General de Supervisión.

De la misma manera, el Reglamento General de Supervisión (RGS) debería prever en su artículo $11^{\circ}$ expresamente la facultad de solicitar información a otras entidades públicas, tal y como se prevé en el TUO de la LPAG.

Por otro lado, las facultades del artículo 240 del TUO de la LPAG que ya estaban atribuidas al OSITRAN por leyes previas, en sus propias normas están definidas con mayor precisión. Por ejemplo, respecto de la facultad de exhibición de documentos, se incluyen expresamente en el artículo 2 a) del Decreto Legislativo 807:

"la exhibición de todo tipo de documentos, incluyendo los libros contables y societarios, los comprobantes de pago, la correspondencia comercial y los registros magnéticos incluyendo, en este caso, los programas que fueran necesarios para su lectura; así como solicitar información referida a la organización, los negocios, el accionariado y la estructura de propiedad de las empresas".

Con relación a la facultad de interrogar, el artículo 2 b) del Decreto Legislativo 807 precisa que puede "Citar e interrogar, a través de los funcionarios que se designe para el efecto, a las personas materia de investigación o a sus representantes, empleados, funcionarios, asesores y a terceros, utilizando los medios técnicos que considere necesarios para generar un registro completo y fidedigno de sus declaraciones, pudiendo para ello utilizar grabaciones magnetofónicas o grabaciones en vídeo".

Con referencia a las inspecciones, define que está habilitado para (artículo 2 c) del DL 807) “examinar los libros, registros, documentación y bienes, pudiendo comprobar el desarrollo de procesos productivos y tomar la declaración de las personas que en ellos se encuentren."

También se prevé, en el artículo 2 c) del Decreto Legislativo 807, al igual que en el TUO de la LPAG, que "En el acto de la inspección podrá tomarse copia de los archivos físicos o magnéticos, así como de cualquier documento que se estime pertinente o tomar las fotografías o filmaciones que se estimen necesarias".

En el caso del OSITRAN se menciona expresamente en el artículo 3 del DL 807 que “para ingresar podrá solicitarse el apoyo de la fuerza pública. De ser necesario el descerraje en el caso de locales que estuvieran cerrados será necesario contar con autorización judicial, la que deberá ser resuelta en un plazo máximo de 24 horas."

Adicionalmente a las previstas en el TUO de la LPAG, OSITRAN tiene las siguientes facultades: De acuerdo al Decreto Legislativo 807 (artículo 2 - A) OSITRAN puede “(...) disponer la difusión de información vinculada a los mismos, siempre que lo consideren pertinente en atención a los intereses de los 
consumidores afectados y no constituya violación de secretos comerciales o industriales". Asimismo, conforme al Artículo 3 del mismo Decreto Legislativo 807, "solicitar información a cualquier organismo público y cruzar los datos recibidos con aquéllos que obtengan por otros medios. De la misma manera, podrán transferir información a otros organismos públicos, siempre que dicha información no tuviera el carácter de reservada por constituir un secreto industrial o comercial".

\section{ii. Medidas provisionales y correctivas}

El artículo 246 del TUO de la LPAG, aborda en un artículo específico el dictado de medidas provisionales y correctivas en el marco de la Actividad de Fiscalización, las cuales deben dictarse, previa habilitación por Ley o Decreto Legislativo, decisión motivada y respetando el principio de proporcionalidad.

En realidad, esta norma debería hacer referencia al principio de razonabilidad previsto en el artículo 1.4 del TUO de la LPAG, que es aplicable no sólo al dictado de medidas cautelares o correctivas, sino a la actividad de fiscalización en general. Según este principio, las medidas provisionales o correctivas deben mantener la debida proporción entre los medios a emplear y los fines públicos que deba tutelar, a fin de que respondan a lo estrictamente necesario para la satisfacción de su cometido.

OSITRAN cuenta con la facultad de dictar medidas cautelares y correctivas.

\section{a. Medidas cuatelares}

OSITRAN cuenta, conforme al artículo $10^{\circ}$ del Decreto Legislativo 807, con la facultad de dictar "medidas cautelares dirigidas a evitar que un daño se torne en irreparable, siempre que exista verosimilitud del carácter ilegal de dicho daño".

Esta habilitación legal justamente reafirma que la previsión general del artículo 157 del TUO de la LPAG es en el marco de procedimientos administrativos. En cambio, esta es una habilitación legal para dictar medidas cautelares también fuera del marco de un procedimiento administrativo.

A su vez, el reglamento de la Ley del OSITRAN, en su artículo $79^{\circ}$ dispone que los órganos del OSITRAN competentes podrán dictar, de ser necesario, cualquier medida cautelar dirigida a evitar que un daño se torne en irreparable, siempre que exista verosimilitud del carácter ilegal de dicho daño. Ello podrá incluir la orden de cesación o la imposición de condiciones determinadas para evitar el daño que pudieran causar las conductas a que el procedimiento se refiere.

Esta norma indica que, para el dictado de dicha medida será de aplicación, en lo pertinente, lo previsto en el Artículo 611 del Código Procesal Civil y que la medida cautelar podrá decretarse aun antes de iniciarse un procedimiento. Sin embargo, dicha medida caducará si no se inicia un proceso de investigación dentro de los 
quince (15) días útiles siguientes de su notificación. En ese sentido, se entiende que reglamentariamente se ha limitado al OSITRAN a dictar medidas cautelares fuera de proceso, solo con miras al inicio de un procedimiento sancionador dentro de los 15 días útiles siguientes del dictado y notificación de la cautelar.

El incumplimiento de la medida cautelar habilita al OSITRAN a aplicar multas coercitivas. En efecto, si el obligado a cumplir con una medida cautelar ordenada por el órgano del OSITRAN correspondiente no lo hiciera, se le impondrá automáticamente una sanción de conformidad con lo establecido en el reglamento que sobre infracciones y sanciones dicte el Consejo Directivo del OSITRAN. Dicha multa deberá ser pagada dentro del plazo de cinco (5) días de notificada, vencidos los cuales se ordenará su cobranza coactiva. Si el obligado persiste en el incumplimiento, el órgano del OSITRAN podrá imponer una nueva multa duplicando sucesiva e ilimitadamente el monto de la última multa impuesta hasta que se cumpla la medida cautelar ordenada y sin perjuicio de poder denunciar al responsable ante el Ministerio Público para que éste inicie el proceso penal que corresponda. Las multas impuestas no impiden al órgano del OSITRAN imponer una multa o sanción distinta al final del procedimiento.

\section{b. Medidas correctivas}

OSITRAN también tiene, conforme a su ley de creación 26917 (art 7.1.c), la facultad de dictar medidas correctivas. "Estas medidas comprenden una gran variedad de modalidades entre las cuales podemos mencionar los siguientes ejemplos: mandatos de cese de actividades, paralización de obras, comiso de bienes, retiro de instalaciones, demolición de edificaciones, publicación de avisos informativos, órdenes de devolución de sumas de dinero, clausura de locales, recomendaciones, advertencias o requerimientos, entre otros" 20.

Las medidas correctivas son actos que la Ley autoriza a dictar a las entidades públicas ante la comprobación de actos irregulares, para revertir los efectos nocivos causados por sus actos $u$ omisiones y reestablecer la legalidad de su conducta. Pueden ser complementarias o reparadoras.

Conforme a las primeras, se revierten los efectos de la conducta infractora, se evita que se produzca un daño o que se produzca nuevamente. Las reparadoras tienen como objeto resarcir las consecuencias patrimoniales negativas directas $o$ indirectas al usuario.

Pueden ser muy similares o las mismas en contenido que las medidas cautelares, diferenciándose sólo en el sustento de su dictado ya, que las cautelares buscan preservar la situación mientras se resuelve respecto del tema y no propiamente revertir efectos nocivos de una presunta conducta infractora.

20 TIRADO BARREDA, José Antonio. "Reflexiones en torno a la potestad de inspección o fiscalización de la administración pública". En Revista Derecho E Sociedad N³7, Lima, 2011, p. 258. 
Sería conveniente que en el Reglamento General de Supervisión del OSITRAN, en el artículo $11^{\circ}$, se establezca expresamente la facultad de dictar medidas cautelares y correctivas en el marco de la Actividad de Supervisión.

Por otro lado, en el Reglamento General de Supervisión del OSITRAN, se desagregan en el artículo $11^{\circ}$ aquellas funciones que son de la entidad y las que son de los inspectores:

Así, entre las facultades de la entidad figuran las siguientes "enumeradas de manera no taxativa":

1. Convocar a las Entidades Prestadoras a participar en las Reuniones de Trabajo;

2. Requerir la información y documentación que permita verificar el cumplimiento de sus obligaciones, la cual será proporcionada dentro de los plazos, condiciones y forma que OSITRAN establezca;

3. Requerir las facilidades al personal autorizado para ejecutar todas las pruebas técnicas y mediciones solicitadas con motivo de una actividad de supervisión, con los aparatos y equipos de la propia empresa y/o con aquellos con que cuente OSITRAN;

4. Requerir la ejecución de los programas informáticos necesarios para la inspección o verificación de la información correspondiente, debiendo las Entidades Prestadoras proporcionar las claves de acceso que estén relacionadas al objeto de la supervisión;

5. Requerir la firma de las Actas de Inspección

6. Efectuar auditorías que permitan verificar el cumplimiento de las obligaciones de las Entidades Prestadoras establecidas en leyes, normas, contratos y convenios;

7. Implementar los sistemas de control que sean necesarios para llevar a cabo la labor de supervisión;

8. Requerir las facilidades necesarias para realizar las actividades de instalación, operación, mantenimiento y retiro de los equipos que sean necesarios para llevar acabo la labor de supervisión;

9. Disponer la instalación de equipos en las instalaciones de las Entidades Prestadoras, y/o en la infraestructura administrada por ésta, siendo responsable de la instalación, operación, mantenimiento y retiro de los mismos;

10. Requerir a las Entidades Prestadoras que preserven la integridad de los equipos que OSITRAN pudiera haber instalado. 
11. Todas aquellas otras que resulten necesarias para el adecuado cumplimiento de sus funciones.

Por otro lado, el personal de supervisión cuenta con las siguientes facultades:

1. Ingresar a las zonas donde se encuentre información relevante que contribuya a la función supervisora;

2. Llevar a cabo los actos necesarios para obtener información relacionada a la materia de supervisión a través de la exhibición o presentación de todo tipo de documentos, incluyendo libros contables, facturas, recibos, comprobantes de pago, registros magnéticos, contratos de alquiler, convenios de pagos de pólizas y en general todo elemento necesario para su revisión; pudiendo exigir la entrega de impresiones, fotocopias, facsímiles, planos, cuadros, dibujos, fotografías, radiografías, filmaciones, microformas tanto en la modalidad de microfilm como en la modalidad de soportes informáticos, y otras reproducciones de audio o video, la telemática en general y demás objetos que recojan, contengan o representen algún hecho, actividad o su resultado;

3. Tomar fotografías o videos donde conste el estado de la infraestructura, o las características operativas de los servicios prestados;

4. Tomar copia de los archivos físicos o magnéticos, así como de cualquier otro documento que sea necesario para los fines de la actividad de supervisión;

5. Efectuar pruebas, analizar las características de los equipos, revisar instalaciones y, en general, llevar a cabo cualquier diligencia que conlleve al cumplimiento del objeto de la actividad supervisora;

6. Tomar y registrar declaraciones de las personas que puedan brindar información relevante sobre la supervisión que se lleva a cabo;

7. Instalar o usar equipos en las instalaciones de las Entidades Prestadoras o en la Infraestructura de Transporte de Uso Público, siempre que ello no afecte la prestación de los servicios involucrados;

8. No identificarse al inicio en los casos de inspección encubierta, pudiendo comportarse como usuarios, potenciales clientes o terceros, entre otros, a fin de lograr el cumplimiento del objeto de la acción supervisora;

9. Todas aquellas otras que resulten necesarias para el adecuado cumplimiento de sus funciones.

A este respecto, es preciso indicar que las facultades del OSITRAN y su personal de Supervisión deben ser expresamente atribuidas por Ley y eso no admite este tipo de cláusulas genéricas descritas como "todas aquellas otras que resulten necesarias para el adecuado cumplimiento de sus funciones". 
Los actos ejercidos sobre la base de facultades genéricas, siempre serán vulnerables de ser impugnados y revertidos en sede judicial.

Con relación a los deberes de las entidades y de los administrados, cabe realzar que uno de los deberes que se señalan expresamente en el TUO de la Ley y no en el Reglamento General de Supervisión es el "deber de imparcialidad y prohibición de mantener intereses en conflicto". Creo que al tratarse de una Actividad y no Procedimiento Administrativo, esta previsión es necesaria. Me explico, para el caso de los procedimientos administrativo, opera las causales de abstención del artículo $99^{\circ}$ del TUO de la LPAG. En el marco de la Actividad de Fiscalización, es relevante evitar conflicto de intereses que puedan afectar el cumplimiento de sus obligaciones y responsabilidades. Esto debería ser añadido en el artículo $12^{\circ}$ del Reglamento de Supervisión.

Respecto de los deberes de los administrados, el TUO de la LPAG no trae mayor novedad respecto de lo previsto en la normativa del OSITRAN. Sin embargo, en el artículo 27 del Reglamento General del OSITRAN, precisa que, “las Entidades Prestadoras a ser supervisadas deben brindar todas las facilidades necesarias para que se ejecuten las actividades de supervisión a cargo de OSITRAN y/o de las Empresas Supervisoras. En caso contrario serán pasibles de sanción administrativa, en tanto que las acciones $u$ omisiones de los representantes y personas que impidan el ejercicio de la función supervisora serán puestas en conocimiento del Ministerio Público para los fines correspondientes".

\section{Derechos de los administrados}

El artículo 242 del TUO de la LPAG se refiere a los derechos de los administrados ante una Actividad de Fiscalización.

El Reglamento General de Supervisión del OSITRAN no tiene un artículo sobre derechos de las entidades prestadoras, a pesar que el artículo $3^{\circ}$ menciona como objeto del Reglamento, establecer las normas que rigen la función supervisora de OSITRAN, los derechos y obligaciones de los supervisados y los procedimientos que se aplicarán en los procesos de supervisión.

Sin embargo, en su texto, se menciona expresamente lo siguiente:

En el artículo 12, denominado "Obligaciones del personal de supervisión", se desprenden los siguientes derechos de las Entidades Prestadoras:

a) Requerir la identificación de los funcionarios a cargo de la fiscalización.

b) Ser informados del objeto de la actividad de supervisión y el motivo de la misma.

Asimismo, en el artículo 19 f) se menciona que la Entidad Prestadora puede formular comentarios pertinentes en el Acta, que serán registrados en ella por el 
supervisor responsable de la inspección y en el inciso g) que la Entidad Prestadora recibirá una copia del Acta.

Sería conveniente que el Reglamento General de Supervisión, incluya un artículo sobre los Derechos, incluyendo los nuevos que figuran en el TUO de la LPAG de: i) Poder realizar grabaciones en audio o video de las diligencias en las que participen; ii) Presentar documentos, pruebas o argumentos adicionales con posterioridad a la recepción del acta de fiscalización; y, iii) Llevar asesoría profesional a las diligencias si el administrado lo considera (que, es un derecho del administrado, pero no requisito de validez de su realización).

\section{Información confidencial}

Con referencia al acceso a información en el marco de las Actividades de Supervisión, el TUO de la LPAG dispone que "el acceso a la información que pueda afectar la intimidad personal o familiar, así como las materias protegidas por el secreto bancario, tributario, comercial e industrial y la protección de datos personales, se rige por lo dispuesto en la Constitución Política del Perú y las leyes especiales".

En ese sentido, consideramos que el tratamiento como información confidencial que le da el Artículo 29 del RGS del OSITRAN, no es suficiente pues existe información confidencial de secreto comercial a la que el Consejo Directivo u otros órganos de OSITRAN pueden tener acceso, pero también existe información como la referida al secreto bancario o tributario a la que no podrán tener acceso, salvo autorización judicial y eso debería ser expresamente mencionado en el Reglamento General de Supervisión y en el Reglamento para la Determinación, Ingreso, registro y Resguardo de Información Confidencial.

\section{Tercerización}

En virtud de la Ley de creación del OSITRAN, esta entidad puede tercerizar las actividades de supervisión.

El artículo 7.2 de la Ley 26917, dispone que “para el adecuado cumplimiento de sus funciones OSITRAN podrá contratar los servicios de entidades públicas o privadas especializadas".

Conforme al artículo $23^{\circ}$ del Reglamento General del OSITRAN, norma reglamentaria de las Leyes 26917, 27332 y 28337, aprobado por el DS 044-2006PCM, “OSITRAN, a través de la Gerencia de Supervisión y Fiscalización, previa autorización de la Gerencia General, puede delegar las funciones de supervisión a entidades públicas o privadas, de reconocido prestigio, incluyendo empresas especializadas, siempre que se garantice la autonomía e idoneidad técnica. La fase resolutoria de la función supervisora es indelegable". 
Asimismo, en su artículo $25^{\circ}$, dispone que, para tercerizar, se debe cumplir con lo siguiente:

1. Suscribir el contrato de locación de servicios.

2. Cumplir con el Reglamento General de Supervisión y demás normas y procedimientos establecidos para la ejecución de las actividades de supervisión en nombre del OSITRAN.

3. Remitir al OSITRAN los informes de supervisión de acuerdo al cronograma establecido en cada contrato de locación de servicios. El informe tiene carácter de Declaración Jurada, sujeto a las responsabilidades de la Ley del OSITRAN y es suscrito por los profesionales que intervienen en los exámenes y actos practicados para la supervisión.

4. Conservar en sus archivos los documentos que sustenten los informes de supervisión, por un período no menor de tres (3) años, contados a partir del año siguiente a aquel en que finalizó el respectivo contrato de locación de servicios.

Asimismo, el artículo 66 del Reglamento General del OSITRAN, norma reglamentaria de las leyes 26917, 27332 y 28337, aprobada por DS 044-2006-PCM en su Tercer párrafo indica que:

"las entidades públicas o privadas, de reconocido prestigio, incluyendo empresas especializadas, a que hace referencia el artículo 23 del presente Reglamento, también podrán ejercer las facultades concedidas a los órganos del OSITRAN, conforme al Título I del Decreto Legislativo $\mathrm{N}^{\circ}$ 807, encontrándose sujetas a las mismas incompatibilidades, restricciones, prohibiciones y limitaciones".

En ese sentido, los terceros supervisores tienen las mismas facultades de supervisión del OSITRAN.

Sin embargo, si en el marco de las Actividades de Fiscalización se requiriera dictar medidas cautelares o correctivas, esto debería ser comunicado al OSITRAN para que proceda conforme a sus atribuciones.

\section{Conclusión de la actividad de fiscalización}

El TUO de la LPAG tiene un artículo que lista las formas de conclusión de la actividad de fiscalización.

1. La certificación o constancia de conformidad de la actividad desarrollada por el administrado.

Al culminar una actividad de fiscalización en la que no se ha identificado algún incumplimiento digno de reportar o corregir. 
2. La recomendación de mejoras o correcciones de la actividad desarrollada por el administrado.

3. La advertencia de la existencia de incumplimientos no susceptibles de ameritar la determinación de responsabilidades administrativas; es decir que no ameritan el iniciar un PAS.

4. La recomendación del inicio de un PAS con el fin de determinar las responsabilidades administrativas que correspondan.

5. La adopción de medidas correctivas.

6. Otras formas según lo establezcan las leyes especiales.

En el Reglamento General de Supervisión del OSITRAN, en cambio, se define cómo culmina cada una de las modalidades de supervisión con Acta de Reunión de Trabajo, Acta de Inspección, Informes de Supervisión o Informe de Hallazgo.

En ese sentido, no correspondería que el OSITRAN modifique su Reglamento General de Supervisión parar añadir un artículo similar.

\section{A modo de conclusión}

Uno de los aspectos del Decreto Legislativo 1272, recogido en el TUO de la LPAG es la regulación general de la actividad de fiscalización, en lo referido a su definición, alcances y límites, así como, también respeto de su sujeción a los principios del TUO de la LPAG; principalmente el de razonabilidad o proporcionalidad.

Hemos analizado el marco legal específico del OSITRAN que es de aprobación previa al Decreto Legislativo 1272, para concluir su conformidad con el TUO de la LPAG y advertir las nuevas facultades con que cuenta a partir de éste.

Destaca en este capítulo sobre la actividad de fiscalización que, a partir de esta norma, las entidades que cuentan con competencia de inspección, independientemente de la nomenclatura aludida, tengan todas las facultades previstas en el artículo $240^{\circ}$ del TUO de la LPAG, incluyendo por ejemplo, la de ampliar o variar durante la inspección el objeto de la misma. Asimismo, destaca el que, entre los derechos de los administrados figure, acorde con las actuales tendencias, el de poder registrar en audio y video todo el acto de inspección.

Indiscutiblemente, este será el capítulo con más impacto en la aplicación del TUO de la LPAG en los próximos tiempos. 